\title{
Primary and secondary thyroid hormone transporters
}

\author{
Anita Kinne, Ralf Schülein, Gerd Krause*
}

\begin{abstract}
Thyroid hormones (TH) are essential for the development of the human brain, growth and cellular metabolism. Investigation of $\mathrm{TH}$ transporters became one of the emerging fields in thyroid research after the discovery of inactivating mutations in the Monocarboxylate transporter 8 (MCT8), which was found to be highly specific for $\mathrm{TH}$ transport. However, additional transmembrane transporters are also very important for TH uptake and efflux in different cell types. They transport TH as secondary substrates and include the aromatic amino acid transporting MCT10, the organic anion transporting polypeptides (e.g. OATP1C1, OATP1A2, OPTP1A4) and the large neutral amino acid transporters (LAT1 and LAT2). These TH transporters characteristically possess 12 transmembrane spanners but due to the strong differing sequences between the three transporter families we assume an identical conformation is not very likely. In contrast to the others, the LAT family members form a heterodimer with the escort protein 4F2hc/CD98. A comparison of sequence proportions, locations and types of functional sensitive features for TH transport discovered by mutations, revealed that transport sensitive charged residues occur as conserved amino acids only within each family of the transporter types but not in all putative TH transporters. Based on the lack of highly conserved sensitive charged residues throughout the three transporter families as a common counterpart for the amino acid moiety of the substrates, we conclude that the molecular transport mechanism is likely organized either a) by different molecular determinants in the divergent transporter types or b) the counterparts for the substrates` amino acid moiety at the transporter are not any charged side chains but other proton acceptors or donators. However, positions of transport sensitive residues coincide at transmembrane helix 8 in the TH transporter MCT8, OATP1C1 and another amino acid transporter, the L-cystine and L-glutamate exchanger $x C T$, which is highly homologous to LAT1 and LAT2. Here we review the data available and compare similarities and differences between these primary and secondary TH transporters regarding sequences, topology, potential structures, trafficking to the plasma membrane, molecular features and locations of transport sensitive functionalities. Thereby, we focus on TH transporters occurring in the blood-brain barrier.
\end{abstract}

\section{Introduction}

Investigation of thyroid hormone $(\mathrm{TH})$ transporters has become one of the emerging fields in thyroid research during the last few years. Molecular studies of TH transporters were enforced after the discovery of inactivating mutations in the TH transporter MCT8 (Monocarboxylate transporter 8). These mutations cause the AllanHerndon-Dudley syndrome (AHDS) [1], which is an Xlinked mental retardation. The affected patients show normal TSH (Thyroid-stimulating hormone, thyrotropin) but elevated $\mathrm{T}_{3}\left(3,3^{\prime}, 5\right.$-triiodo-L-thyronine) and

\footnotetext{
* Correspondence: gkrause@fmp-berlin.de

Leibniz-Institut für Molekulare Pharmakologie (FMP), Robert-Roessle-Str. 10, 13125 Berlin, Germany

Full list of author information is available at the end of the article
}

decreased $\mathrm{T}_{4}\left(3,3^{\prime}, 5,5^{\prime}\right.$-tetraiodo-L-thyronine) serum levels [2-6].

$\mathrm{TH}$ are essential for the development of the human brain, growth and cellular metabolism. A dysfunction in the availability of $\mathrm{TH}$ during early embryonic development leads to neurological deficiency [7]. In the brain, $\mathrm{TH}$ are important e.g. for the timely migration of neurons, formation of synaptic contacts and myelination [8]. Neurons are the major target cells for $T_{3}$ during brain development. According to current concepts, the prohormone $T_{4}$ enters the neighbouring astrocyte and deiodinase 2 converts $T_{4}$ to the active form $T_{3}$ which is then transported into neurons by MCT8 [9].

An impaired uptake of $\mathrm{T}_{3}$ in MCT8-expressing central neurons could explain the neurological deficits found in
C Biomed Central

() 2011 Kinne et al; licensee BioMed Central Ltd. This is an open access article distributed under the terms of the Creative Commons Attribution License (http://creativecommons.org/licenses/by/2.0), which permits unrestricted use, distribution, and reproduction in any medium, provided the original work is properly cited. 
AHDS patients [1,3]. Surprisingly, the corresponding Mct8-deficient mice show the endocrine changes only, but not the neurological phenotype, observed in affected humans. Symptoms of hyperthyroidism in the peripheral tissues in combination with symptoms of hypothyroidism in the central nervous system were shown in mice. The brain uptake of exogenous $\mathrm{T}_{3}$ is also markedly reduced, whereas the uptake of $\mathrm{T}_{4}$ shows $50 \%$ transport activity in comparison to the wild type mice [10-12].

On the basis of these data it was assumed that additional TH transporters ("secondary TH transporters") or differences in their expression patterns and substrate specificity can compensate the loss of Mct8 in mice [13]. Finally, it became obvious that secondary TH transporters are also very important for $\mathrm{TH}$ uptake and efflux in different cells types. Whereas the primary $\mathrm{TH}$ transporter MCT8 is currently known to be highly specific for TH only [14], the secondary $\mathrm{TH}$ transporters are also able to transport different kinds of amino acids and comprise the aromatic amino acid transporting MCT10, the organic anion transporting polypeptide transporters (e.g. OATP1C1, OATP1A2, OPTP1A4), and the large neutral amino acid transporters (LAT1 and LAT2).

Another amino acid transporter, the sodium independent exchanger of L-cystine and L-glutamate (xCT), which can even transport negatively charged amino acids, is also considered here, since $\mathrm{xCT}$ shows close similarities to LAT transporters regarding molecular features and plasma membrane trafficking mechanism.

Therefore, we here review the data available on similarities and differences between the primary and secondary $\mathrm{TH}$ transporters regarding sequence, trafficking to the plasma membrane, molecular features, predicted membrane topologies, potential structures and functionalities. Thereby, our focus here is on $\mathrm{TH}$ transporters occurring in the blood-brain barrier (BBB).

\section{Expression patterns of primary and secondary TH transporters}

It was shown in the brain that MCT8 expression in neurons is essential for neuronal uptake of $\mathrm{T}_{3}[15]$. The reduced brain uptake of $\mathrm{T}_{3}$ and $\mathrm{T}_{4}$ in Mct8-deficient mice suggests that MCT 8 transports $\mathrm{TH}$ across the BBB. Roberts et al. could show an expression of MCT8 in cerebral microvessels and demonstrated the expression of MCT8 at the BBB in the human, mouse, and rat brain [13]. These expression profiles support the suggestion that MCT8 does not only play a major role in $\mathrm{TH}$ action in the brain in humans and rodents but also in the uptake of $\mathrm{TH}$ in the brain across the $\mathrm{BBB}$ in humans. MCT 8 is also expressed in the thyroid, liver, testis, and in the skeletal muscle (table 1). Another member of the MCT family which transports $\mathrm{TH}$,
MCT10, shows overlapping expression patterns with MCT8, except that MCT10 has not been detected in the thyroid, brain and testis (table 1 ).

OATP1C1 like MCT8 is expressed at the BBB in mouse and rat, but to a much lesser extent at the human BBB [13]. The strong expression of OATP1C1 in the rodent but less so in the human BBB could explain why Mct8-deficient mice do not show the neurological changes found in AHDS patients. The OATP family members OATP1A2 and OATP1A4 are also expressed in the brain and show transport of TH (table 1) [16].

The TH transporters LAT1 and LAT2 are expressed in various tissues, e.g. in luminal and abluminal membranes of brain capillary endothelial cells, placenta, and intestine, whereas LAT1 also shows high expression levels in tumour cells (table 1). Both transporters are expressed at the BBB, whereby LAT1 expression is higher than LAT2 [17] (figure 1). LAT1 and LAT2 form a heterodimer with the escort protein, 4F2hc (4F2 heavy chain, CD98), which is ubiquitously expressed, e.g. in tumours, brain, kidney, intestine, and placenta (table 1) $[18,19]$.

The amino acid transporter $\mathrm{xCT}$ is also expressed in the brain (table 1) $[20,21]$ and it has been suggested that $\mathrm{xCT}$ is up-regulated in glial cells upon the oxidative stress and plays an essential role to protect neurons against oxidative stress [22].

\section{Topology and structures of TH transporters}

The TH transporters considered here show a common topology by comprising 12 transmembrane helices (TMHs) while the $\mathrm{N}$ - and $\mathrm{C}$-terminal tails are located intracellularly, like a vast number of other known transporters of the major facilitator superfamily (MFS) (see transporter database http://www.tcdb.org/superfamily. php). The MFS is an evolutionary diverse superfamily that includes over 10,000 sequenced members which catalyze uniport, symport and antiport transport mechanisms.

MCT8 and MCT10 belong to the MFS subgroup of Monocarboxylate transporter family. Since the monocarboxylate transport for the members MCT1-4 is proton linked, these MCT transporters are not further considered here.

The OATP family members Oatp1a4 and Oatp1a5 were the first cloned TH transporters [23]. Although the OATP family also belongs to the MFS in terms of sequence similarity it is more distant from MCT8 and MCT10.

LAT1 and LAT2 are even more distant to MCT8. They are members of the Amino Acid-PolyamineOrganocation (APC) superfamily and transport sodium-independent large neutral amino acids such as phenylalanine, tyrosine, leucine, arginine and 
Table 1 Tissue distribution of TH transporters from the MCT (MCT8 and MCT10), OATP (OATP1C1, OATP1A2, OATP1A4), and LAT (LAT1 and LAT2) family and of the XCT transporter and the escort protein 4F2hc.

\begin{tabular}{|c|c|c|c|}
\hline Gene & Protein & Localization & References \\
\hline SLC16A2 & MCT8 & liver, kidney, brain, heart, skeletal muscle, placenta, thyroid, testis & {$[14,15,33,64-68]$} \\
\hline SLC16A10 & MCT10 & intestine, kidney, liver, skeletal muscle, heart, placenta, pancreas & [67-69] \\
\hline SLCO1C1 & OATP1C1 & brain, testis, cochlea & {$[38,39]$} \\
\hline SLCO1A2 & OATP1A2 & brain, liver, kidney, intestine & [70-72] \\
\hline SLCO1A4 & OATP1A4 & liver, brain, testis, ovaries, retina & {$[23,70,73]$} \\
\hline SLC7A5 & LAT1 & $\begin{array}{l}\text { multiple (tumours, brain, spleen, placenta, testis, colon, kidney, intestine, stomach, ovary, thymus, not } \\
\text { liver) }\end{array}$ & [74-81] \\
\hline SLC7A8 & LAT2 & kidney, placenta, brain, intestine, testis, ovary, liver, heart, skeletal muscle, lung, stomach & {$[74,79-83]$} \\
\hline SLC7A11 & $x \subset T$ & brain, kidney, activated macrophages, duodenum & {$[20,84,85]$} \\
\hline Gene & $\begin{array}{l}\text { Escort } \\
\text { protein }\end{array}$ & Localization & Reference \\
\hline SLC3A2 & 4F2hc (CD98) & multiple (tumours, brain, intestine, kidney, liver, skeletal muscle, ovary, placenta, testis...) & [74] \\
\hline
\end{tabular}

tryptophan from extracellular fluids into the cell, when associated with SLC3A2/4F2hc. The glutamate transporting $\mathrm{xCT}$ also belongs to the APC family and shows high similarities to the LATs on the molecular level.
There is a lack of detailed experimental structural information for all $\mathrm{TH}$ transmembrane transporters. Therefore, the crystal structure of the Glycerol-3-phosphate transporter (GlpT, PDB code 1PW4 [24]), another member of the MSF superfamily, has been used as a

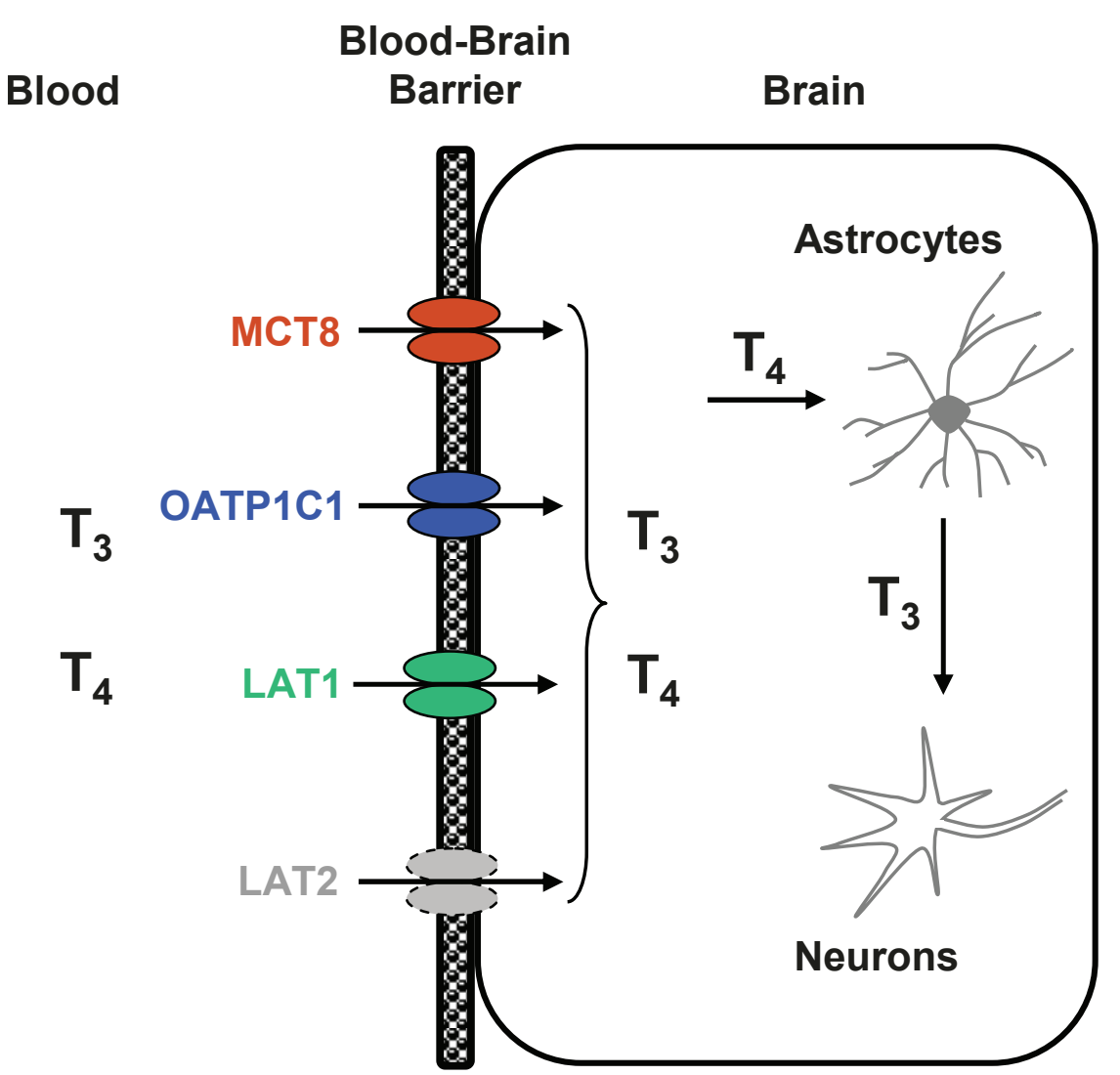

Figure 1 Illustration of the TH transporters expressed at the blood-brain barrier (BBB). The TH transporters MCT8, OATP1C1, LAT1, and LAT2 are expressed at the BBB, whereby LAT2 shows lower expression levels than the LAT1. The prohormone $T_{4}$ enters the astrocyte and is converted to the active form $T_{3}$ by an outer ring deiodination. According to current concepts, $T_{3}$ enters the neurons by the TH transporter MCT8. 
structural template for homology models for MCT1 [25], MCT8 [26], and OATP1C1 [27]. Although it has been suggested that the substrate translocation at GlpT is associated with conformational changes by an alternating access mechanism with a rocker-switch type of movement of the $\mathrm{N}$ - and $\mathrm{C}$-terminal domains $[23,25]$, details for the particular $\mathrm{TH}$ transporters are not known yet.

Among the numerous X-ray structures of bacterial transporters the high-resolution three-dimensional structures of another MFS type, the lactose $\mathrm{H}^{+}$symporter (LacY) $[28,29]$, also shows the closest structural homology to GlpT. The crystal structure of an APC family transporter, the proton-coupled broad-specificity amino acid transporter apo-ApcT [30], shows the 12 TMHs in an inward-facing apo state. It shows a structural similarity to the 12 TMHs within the crystal structure of a bacterial homologue for neurotransmitter transporters, the sodium-dependent leucine transporter (LeuT) from Aquifex aeolicus[31]. The ion independent GlpT structure possesses a single binding site for the substrate. The other available structures from MSF and APC families are from proton- or ion-coupled transporters and contain additional binding sites for the symported protons or ions.

\section{Substrate spectra of TH transporters show a broad range}

So far cellular uptake of $\mathrm{TH}$ has been shown for the monocarboxylate transporters MCT8 and MCT10, the organic anion transporting polypeptides, e.g. OATP1C1, OATP1A2, and OATP1A4, and the heterodimeric amino acid transporters LAT1 and LAT2 [16].

MCT8 was identified as the first specific transporter of $\mathrm{T}_{4}$ and $\mathrm{T}_{3}$ and was found to transport their inactive $\mathrm{TH}$ metabolites such as $\mathrm{rT}_{3}$ (3,3',5-triiodo-L-thyronine) and $3,3^{`}-\mathrm{T}_{2}$ (3,3`-diiodo-L-thyronine) [14]. Thereby, the transport of $\mathrm{T}_{3}$ is higher than of $\mathrm{T}_{4}$ or $\mathrm{rT}_{3}$, respectively $\left(\mathrm{T}_{3}>\mathrm{T}_{4}>\mathrm{rT}_{3} \sim 3,3^{\prime}-\mathrm{T}_{2}\right.$ ) (table 2) [14]. In order to be

Table 2 Uptake of iodothyronines by TH transporters expressed at the blood-brain barrier. The levels of TH transport are indicated as follows: +++ high uptake rate, ++ modest uptake rate, and + low uptake rate; n.d., not determined.

\begin{tabular}{|c|c|c|c|c|c|c|}
\hline \multirow[t]{2}{*}{ Protein } & \multicolumn{4}{|c|}{ lodothyronines } & \multirow[t]{2}{*}{ Species } & \multirow[t]{2}{*}{ References } \\
\hline & $\begin{array}{c}3,3^{\prime}- \\
T_{2}\end{array}$ & $\mathrm{~T}_{3}$ & $r T_{3}$ & $\mathrm{~T}_{4}$ & & \\
\hline MCT8 & $+/+$ & $\begin{array}{c}+++/++ \\
+\end{array}$ & $\begin{array}{c}+/+ \\
+\end{array}$ & $\begin{array}{c}++/+ \\
+\end{array}$ & human/rat & {$[14,86]$} \\
\hline OATP1C1 & n.d. & + & +++ & +++ & $\begin{array}{l}\text { human, rat, } \\
\text { mouse }\end{array}$ & [37-39] \\
\hline LAT1 & +++ & ++ & ++ & + & human & {$[43]$} \\
\hline LAT2 & +++ & ++ & ++ & + & mouse & [43] \\
\hline
\end{tabular}

transported by human MCT8, substrates require at least one iodine atom per aromatic ring preferably at their 3 and 3 'position, respectively [26]. Neither thyronamines (except 3-iodothyronamine [32]), decarboxylated metabolites of iodothyronines, nor $\mathrm{TH}$ derivatives lacking both chiral center and amino group, are substrates for MCT8 [26,32]. MCT10 was first identified as a T-type transporter for aromatic amino acids [33] and later Friesema et al. showed that MCT10 is at least as active for TH transport as MCT8 [34].

The TH transporting OATP family members show a broader substrate spectrum, e.g. in addition to $\mathrm{TH}$ they transport bile acids, steroid hormones [35] and drugs [36]. Functional transport analysis of OATP1C1 revealed that $\mathrm{T}_{4}$ and $\mathrm{rT}_{3}$ are high affinity substrates of OATP1C1, whereas the specific uptake of $\mathrm{T}_{3}$ is about 5 -fold less than that of $\mathrm{T}_{4}$ and $\mathrm{rT}_{3}\left(\mathrm{~T}_{4} \sim \mathrm{rT}_{3}>\mathrm{T}_{3}\right)$ [37-39] (table 2). It has been suggested that OATP1C1 is primarily responsible for $\mathrm{T}_{4}$ uptake from the blood into the brain across the $\mathrm{BBB}$ where it is locally converted to the active $\mathrm{T}_{3}$, which is in turn transported into neurons by MCT8 [40].

LAT1 and LAT2 transport large neutral amino acids and amino acid related compounds, whereas LAT2 also transports small amino acids [41,42]. Functional analysis of LAT1 could demonstrate the iodothyronine uptake, which decreased in the order $3,3^{\prime}-\mathrm{T}_{2}>\mathrm{rT}_{3} \sim \mathrm{T}_{3}>\mathrm{T}_{4}$. Smaller increments in iodothyronine uptake were noted in transport mediated by LAT2 (table 2) [43].

The amino acid transporter $\mathrm{xCT}$ is responsible for the cystine transport through the plasma membrane $[44,45]$. It mediates an amino acid exchange and prefers cystine and glutamate as its substrates [46].

\section{Similarities and Differences of TH transporters on Molecular Level}

\section{Sequences}

A comparison of the different sequence proportions and features among the discussed TH transporters is shown in figure 2. Sequence lengths, proportions and known sensitive features of transport differ between the three TH transporter families (MCT, OATP, and LAT). Due to the very high sequence similarity to the LAT sequences, we also considered the $\mathrm{xCT}$ sequences here.

Sequence alignment reveals that the MCT8 and especially the human MCT8 contain a very large $\mathrm{N}$-terminal tail, for which the function is still unknown [47]. Both TH transporting MCT family members, MCT8 and its close homolog MCT10, do not contain extracellular glycosylation sites [34].

Other secondary TH transporters such as those from the OATP family are less similar. They show larger extracellular loops (EL) with numerous conserved cysteines in EL2, EL5 and EL6 (yellow bars in figure 2) that are probably disulfide bridged. Moreover, chances 


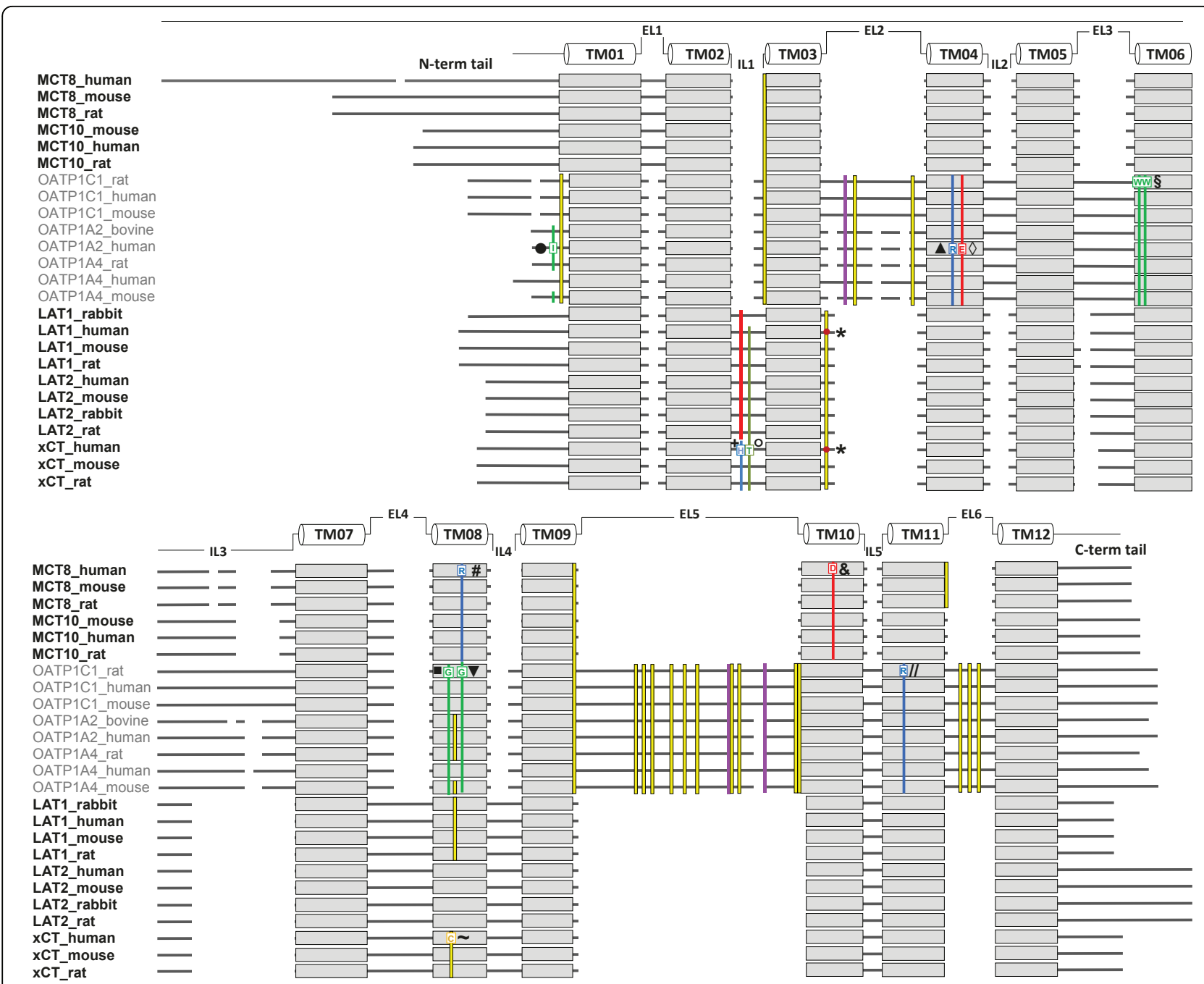

Figure 2 Comparison of sequence proportions and functional sensitive features of primary and secondary TH transporters. Sequence scheme of $\mathrm{TH}$ transporters expressed at the blood-brain barrier (BBB) is aligned according to the sequences of common 12 transmembrane spanners (pale grey boxes). Sequence lengths, proportions and known sensitive features of transport differ between the three TH transporter families (MCT, OATP, and LAT). The XCT sequences are very homologous to LATs and are therefore added. The human MCT8 possesses a very large N-terminal tail at the intracellular portion. Intra- and extracellularly conserved cysteines are marked in yellow bars. N-glycosylation sites of the OATP family are conserved at large extracellular loops EL2 and EL5 (magenta bars). The proven disulfide bridge formed by the LAT and xCT family to the escort protein 4F2hc are conserved in the EL2 (C165-LAT1_human [49] or C158-xCT_human [50] marked by red dot* at yellow bar). Sensitive positions for TH transport identified by mutations are highlighted: MCT8_human: R445A(\# blue bar, TMH8 [26]) and D498A (\& red bar, TMH10 [26]), the sensitive arginine and aspartate are conserved at the MCT8 and MCT10 group; Oatp1C1_rat: W277A and W278A (§ green bars, TMH6 [27]), G400A and G410A (- and $\mathbf{v}$ green bars, TMH8 [30]), R601A (// blue bar, TMH11 [27]); OATP1A2_human: 113T ( $\diamond$ N-terminal tail [63]), R168C ( $\bullet$ blue bar, TMH4 [58]), E172D ( $\diamond$ red bar, TMH4 [63]). The isoleucine at position 13 (green bar, N-terminal tail) is only conserved at the OATP1A2 group, while the sensitive tryptophan (green bars), arginines (blue bars) and glutamate (red bar) are conserved within the OATP family. At the human $\mathrm{xCT}$ may lie close to the substrate binding site H110 (+ blue bar [21]) and T112 ( $\mathrm{O}$ green bar [21]) in IL1 and the C327 ( yellow bar [62]) at TMH8. The accession numbers of these proteins are NM_006517.3 (MCT8_human), NM_009197.2 (MCT8_mouse), NM_147216.1 (MCT8_rat), NM_018593.4 (MCT10_human), NM_001114332.1 (MCT10_mouse), Q91Y77 (MCT10_rat), NM_017435.4 (OATP1C1_human), NM_021471.2 (OATP1C1_mouse), NM_053441.1 (OATP1C1_rat), NM_134431.3 (OATP1A2_human), NM_174654.2 (OATP1A2_bovine), AF205071.1 (OATP1A4_human), NM_030687.1 (OATP1A4_mouse), NM_131906.1 (OATP1A4_rat), BC039692.2 (LAT1_human), BC026131.1 (LAT1_mouse), CH473972.1 (LAT1_rat), NM_001082120.1 (LAT1_rabbit), BC052250.1 (LAT2_human), BC059004.1 (LAT2_mouse), NM_053442.1 (LAT2_rat), NM_001082682.1 (LAT2_rabbit), NM_014331.3 (xCT_human), NM_011990.2 (xCT_mouse), NM_001107673.2 (xCT_rat). 
are that several conserved glycosylation sites in EL2 and EL5 are responsible for appropriate traffic of this transporter type towards the cell membrane (magenta bars in figure 2).

The transporters that belong to the APC superfamily, such as LAT1/2 and $\mathrm{xCT}$, are even more evolutionary distant from MCT8. Like the other TH transporters they possess 12 transmembrane $\alpha$-helical spanners but for suitable membrane expression they need the one helix transmembrane spanner escort protein $4 \mathrm{~F} 2 \mathrm{hc}$ [48-50]. This transporter type lacks any glycosylation site since the glycosylation sites are only comprised at the large extracellular portion of 4F2hc. Thus, both transporter types (LAT and $\mathrm{xCT}$ ) are in fact tightly associated by a 13th TMH that is provided by the escort protein 4F2hc. This odd number of transmembrane segments might be one reason why the potential intracellular loop 1 (IL1) between TMH2 and TMH3 is organized as a re-entrant loop in the $\mathrm{xCT}$. In a detailed experimental study elucidating the topology of $\mathrm{xCT}$ [21] it was shown that histidin 110 in IL1 (marked + in figure 2) and threonin 112 (marked ${ }^{\circ}$ in figure 2 ) are spatially located in human $\mathrm{xCT}$ in such a way that they are accessible from the extracellular side. At the $\mathrm{xCT}$, a part of IL1 is interposed between the transmembrane segments in such a manner that the two residues are accessible from the extracellular side.

The number and properties of residues at IL1 are highly conserved among $\mathrm{xCT}$ and LAT1/2. Moreover, at the corresponding amino acid positions, where extracellular accessibility was shown in $\mathrm{xCT}$ (H110 and T112), the hydrophilic residues aspartate and serine appear in LAT1 and LAT2 respectively (red and grey bars at IL1 in figure 2). Therefore it is feasible that the IL1 may also functions as a re-entrant loop in LAT1 and LAT2.

\section{Escort proteins}

Not only differences in the transport of $\mathrm{TH}$ within $\mathrm{TH}$ transporters are known, but the trafficking mechanisms of these transporter proteins towards the plasma membrane differ also. Trafficking of integral membrane proteins to the plasma membrane is mediated by the secretory pathway. At the beginning, proteins are integrated into the membrane of the endoplasmatic reticulum and are then delivered in the membrane of vesicles through the individual compartments of the Golgi apparatus to the plasma membrane. MCT8, MCT10, LAT1, and LAT2 are non-glycosylated proteins, whereas the OATPs possess potential glycosylation sites [51] (figure 2). Normally, glycosylations are essential for trafficking whereby the trafficking mechanisms for the two $\mathrm{TH}$ transporters from the MCT and the LAT families are organized differently. In the case of MCT8 and MCT10 it is speculated that the large $\mathrm{N}$-terminal tail might contain features that facilitate trafficking towards the membrane. Other transporters of the MCT family such as MCT1 and MCT4, which do not transport TH but other substrates e.g. lactate, pyruvate and ketone bodies [52], require an association with the escort protein CD147 for efficient cell surface expression [53] instead. In contrast to the TH transporting MCT family members, the two LAT transporters also need an escort protein for efficient cell surface translocation, the 4F2hc $[18,19]$.

The two escort proteins 4F2hc and CD147 share a common topology. The amino-terminus of $4 \mathrm{~F} 2 \mathrm{hc}$ is located intracellularly, whereas the very large extracellular carboxy-terminus [48] contains four potential glycosylation sites [54]. Thus, 4F2hc is a multifunctional type II membrane glycoprotein [55]. In the heterodimer complex between LAT1/2 and 4F2hc the 12 helix transport protein is called the light chain and the glycosylated escort protein $4 \mathrm{~F} 2 \mathrm{hc}$ is called the heavy chain. The heavy chain can form heterodimers with six different non-glycosylated light chains like LAT1, LAT2, y +LAT1, y+LAT2, asc1, and xCT [48].

Both subunits of the heterodimer between the L-type amino acid transporters build a covalent bond via a disulfide bridge through the cysteine residue 109 of the extracellular region of human 4F2hc and the cysteine residue 165 in the second extracellular loop localized between the TMH3 and TMH4 of rat Lat1 (red dot and * in figure 2) $[48,49]$. This cysteine residue is conserved in all sequences of LAT1, LAT2 and also in all $\mathrm{xCT}$ sequences in EL2 (yellow bar in figure 2).

Although these two subunits of the heterodimeric transporters are joined by the highly conserved disulfide bridge, site-directed mutagenesis of these two cysteines on either LAT1 or 4F2hc does not inhibit amino acid transport [56].

Moreover, according to the high sequence homology, it could be shown that the corresponding cysteine in human XCT (cysteine 158, red dot and "in figure 2) [57] also forms a disulfide bridge to 4F2hc.

\section{Functional data for amino acids potentially involved in substrate interaction and functional transport}

Different functional studies of TH transporters could identify amino acid residues potentially involved in substrate interaction. To gain insights into structure-function relationship in $\mathrm{TH}$ transport, we designed the first structural model for human MCT8. Thereby, the conserved and charged amino acids R445 at TMH8 (marked \# in figure 2) and D498 at TMH10 (marked \& in figure 2) have been identified as being involved in substrate interaction. An abrogated $T_{3}$ transport by the alanine mutants R445A and D498A supported their predicted 
role in substrate recognition, although both mutants were exposed to the cell surface [26].

The sensitive arginine (blue bar) and aspartate (red bar) are conserved at the MCT8 and MCT10 group in TMH8 and TMH10, respectively (figure 2). The MCT8 model allows to identify transport characteristics of $\mathrm{TH}$ and to rationalize potential interactions of amino acids including those mutated in patients with AHDS.

In the high-affinity $\mathrm{T}_{4}$ transporter Oatp1c1 Westholm et al. identified amino acid residues to be critical for $\mathrm{T}_{4}$ transport and demonstrated the presence of high and low affinity binding sites [27]. In their study they mapped rat Oatp1c1 substrate interacting sites. W277 and W278 $\left(\$\right.$ in figure 2 ) were shown to play a major role in $\mathrm{T}_{4}$ transport with direct binding effects on one binding site.

Oatp1c1 mutations that reach the cell membrane but affect the transport function such as G400A/V and G410A/V at TMH8 (marked $\boldsymbol{~ a n d ~} \mathbf{v}$ in figure 2) were proposedly involved in transport kinetics. Their alanine and also valine mutants displayed wild type-like uptake activity but exhibit diminished $\mathrm{T}_{4}$ transport at high substrate concentrations. The authors suggested that a substrate binding site might collapse or is turned to inability to convert between input and output states. Based on mutants of the conserved arginine R601 (marked // in figure 2) at TMH11 of rat Oatp1c1 the authors suggested that this arginine may serve within OATP members as a countercharge for anionic binding to OATP1C1 [27]. Genetic variations by Single nucleotide polymorphisms (SNPs) have been detected to be involved in disturbed substrate transport like methotrexate transport at human OATP1A2 [58] such as R168C at TMH4 [58] (marked $\triangle$ in figure 2). Recently it has been proven that some of these SNPs such as I13T at the intracellular $\mathrm{N}$-terminal tail (marked $\bullet$ in figure 2), and E172D at TMH4 (marked $\diamond$ in figure 2), also effect the $\mathrm{T}_{3}$ and $\mathrm{T}_{4}$ transport [59].

Our sequence comparison scheme showed that the isoleucine (marked $\bullet$ in figure 2) at amino acid position 13 at the $\mathrm{N}$-terminal tail is only conserved at the OATP1A2 group (green bar in figure 2), while the other identified $\mathrm{TH}$ sensitive residues such as arginine (blue bars in figure 2) and glutamate (red bar in figure 2) located at TMH4, the two tryptophans (green bars in figure 2) at TMH6, the two glycines (green bars) at TMH8 and the arginine (blue bar) in TMH11 are conserved within the OATP family.

Thereby it is noticeable that the TH transport sensitive position glycine 410 (marked \&\#9679 in figure 2) of rat Oatp1c1 in TMH8 corresponds to the position of the transport sensitive arginine 445 (marked \# in figure 2) in TMH8 at human MCT8.

Boado et al. identified amino acids in the L-type amino acid transporter LAT1 from rabbit, which are potentially involved in trafficking mechanisms to the plasma membrane. They showed that the cysteine residue 439 (corresponding to C443 in human LAT1) plays a significant role at TMH11 in either folding or insertion of the transporter protein in the plasma membrane [56]. Mutagenic analysis of the amino acids G219 and W234 in rabbit LAT1, which differ in relation to the human or rat LAT1, demonstrated marked changes in the affinity and capacity of LAT1 [60]. In order to identify domains involved in recognition of the light chains, LAT1, LAT2, and y+LAT2 by 4F2hc were investigated by Bröer et al.. They suggested that extracellular domains of the 4F2hc are mainly responsible for recognition of light chains other than LAT1 and that the extracellular domain ensures proper translocation to the plasma membrane [61]. Functional data for $\mathrm{xCT}$ demonstrated that H110 located in IL1 which here also represents the re-entrant loop (marked + in figure 2) may lie close to the substrate binding/permeation pathway of $\mathrm{xCT}$ [21]. Studies of the cysteine residue 327 at TMH8 of $\mathrm{xCT}$ (marked $\sim$ in figure 2 ) indicated that it is also located close to the substrate binding site of $\mathrm{xCT}$ [62]. This transport sensitive cysteine at TMH8 is conserved in $\mathrm{xCT}$ and LAT1 transporters but not in LAT2. In addition, it occurs sporadically at the OATP group.

Residues that are sensitive for $\mathrm{TH}$ transport have been found for MCT8 on TMH8 and TMH10 and priorily on TMH4, TMH6, TMH8 and TMH11 for Oatplcl. Until now, no TH transport sensitive residues have been reported for LAT1 and LAT2. For the highly homologous $\mathrm{xCT}$ relevant residues for substrate transport have, however, been identified at the re-entrant loop IL1 and on TMH8. When comparing the transport sensitive features by mapping them on a sequence alignment scheme (figure 2), it becomes clear that the identified residues are almost only conserved within one particular $\mathrm{TH}$ transporter family. None of the sensitive residues are highly conserved across all three considered families. However, the location of a $\mathrm{TH}$ sensitive glycine at TMH8 of the Oatp1c1 and a substrate sensitive cysteine at TMH8 of the $\mathrm{XCT}$ corresponds to a similar region, where in TMH8 of the MCT8 a TH transport sensitive arginine was found (figure 2).

\section{Conclusions}

A comparison of $\mathrm{TH}$ transporter sequences reveals that with the exception of MCT10 secondary $\mathrm{TH}$ transporters belonging to different transporter type families are more divergent to the primary TH transporter MCT8. All different endogenous substrates that are transported by these diverse transporters contain at least one common molecular feature, namely the amino and carboxylate functional group of amino acids. A comparison of locations and types of the identified sensitive $\mathrm{TH}$ 
transporting residues revealed that the known positive or negative charged residues occur as conserved amino acids within each of the transporter types, but not over all TH transporters. Due to the fact that highly diverse amino acid properties (arginine and glycine respectively) have been identified as sensitive for $\mathrm{TH}$ transport at a corresponding position of TMH8 for MCT8 and Oatp1c1, we presume that molecular details of the translocation mechanisms are varying between MCT8 and Oatp1c1. From the divergent sequence features among the three secondary $\mathrm{TH}$ transporter types and the lack of any highly conserved sensitive positively or negatively charged residues as a common counterpart for the amino acid moiety of the substrates, we conclude that the molecular transport mechanisms are likely organized either a) by different molecular determinants in the divergent transporter types or b) the counterpart for amino acid moiety of the substrates at the transporter are not charged side chains but other proton acceptors or donators. Moreover, even though the TH transporters share the common 12 transmembrane spanners, an identical conformation for all $\mathrm{TH}$ transporters is not very likely, particularly at least for the LAT family exhibiting an associated 13th transmembrane helix that is provided by the escort protein. A distinct conformation of the two LATs is also supported by the findings for the homologous $\mathrm{xCT}$ suggesting a re-entrant function of the IL1. On the other hand the coincidence of sensitive positions for substrate transport at TMH8 (although by divergent residues) in the different $\mathrm{TH}$ transporters MCT8, OATP1C1 and even in $\mathrm{xCT}$ could at least be a hint for shared molecular transport events executed at a comparable interior site on TMH8 of the transporters considered here.

Therefore, a detailed knowledge of molecular mechanisms of $\mathrm{TH}$ translocation through the membrane transporting proteins by investigation of structure-function relationships between different substrates and their targets is of vital importance to understand the molecular reasons for defects in $\mathrm{TH}$ transport. In this respect, future investigations of the molecular mechanisms for different substrate transport in the divergent TH transporters are of great importance to clarify the structuralfunctional properties of $\mathrm{TH}$ transport.

\section{Abbreviations}

AHDS: Allan-Herndon-Dudley syndrome; APC superfamily: Amino AcidPolyamine-Organocation superfamily; asc1: asc-type amino acid transporter 1; BBB: blood-brain barrier; LAT: L-type amino acid transporter; MCT: Monocarboxylate transporter; MFS: major facilitator superfamily; OATP: organic anion transporting polypeptide; SNPs: Single nucleotide polymorphisms; TMH: transmembrane helix; $\mathrm{rT}_{3}$ : 3,3',5'-triiodo-L-thyronine; 3,3'- $T_{2}$ : 3,3'-diiodo-L-thyronine; $T_{3}$ : 3,3',5-triiodo-L-thyronine; $T_{4}$ : 3,3',5,5'tetraiodo-L-thyronine; TH: thyroid hormone; TSH: Thyroid-stimulating hormone, thyrotropin; 4F2hc: 4F2 heavy chain, CD98; xCT: cystine/glutamate exchanger; $y+L A T 1: y(+)$ L-type amino acid transporter 1 .
}

\section{Acknowledgements}

This article has been published as part of Thyroid Research Volume 4 Supplement 1, 2011: New aspects of thyroid hormone synthesis and action. The full contents of the supplement are available online at http://www. thyroidresearchjournal.com/supplements/4/S1

\section{Authors' contributions}

AK wrote the draft, analyzed the data, prepared the figures, data evaluation and discussion; RS wrote the draft, data discussion, project coordination; GK wrote the draft, analyzed the data, data evaluation and discussion, project coordination.

\section{Competing interests}

The authors declare that they have no competing interests.

Published: 3 August 2011

\section{References}

1. Friesema EC, Grueters A, Biebermann H, Krude H, von Moers A, Reeser M, Barrett TG, Mancilla EE, Svensson J, Kester MH, et al: Association between mutations in a thyroid hormone transporter and severe X-linked psychomotor retardation. Lancet 2004, 364:1435-1437.

2. Brockmann K, Dumitrescu AM, Best TT, Hanefeld F, Refetoff S: X-linked paroxysmal dyskinesia and severe global retardation caused by defective MCT8 gene. J Neurol 2005, 252:663-666.

3. Dumitrescu AM, Liao XH, Best TB, Brockmann K, Refetoff S: A novel syndrome combining thyroid and neurological abnormalities is associated with mutations in a monocarboxylate transporter gene. Am J Hum Genet 2004, 74:168-175.

4. Schwartz CE, May MM, Carpenter NJ, Rogers RC, Martin J, Bialer MG, Ward J, Sanabria J, Marsa S, Lewis JA, et al: Allan-Herndon-Dudley syndrome and the monocarboxylate transporter 8 (MCT8) gene. Am J Hum Genet 2005, 77:41-53.

5. Herzovich V, Vaiani E, Marino R, Dratler G, Lazzati JM, Tilitzky S, Ramirez P, lorcansky S, Rivarola MA, Belgorosky A: Unexpected peripheral markers of thyroid function in a patient with a novel mutation of the MCT8 thyroid hormone transporter gene. Horm Res 2007, 67:1-6.

6. Maranduba CM, Friesema EC, Kok F, Kester MH, Jansen J, Sertie AL, Passos-Bueno MR, Visser TJ: Decreased cellular uptake and metabolism in Allan-Herndon-Dudley syndrome (AHDS) due to a novel mutation in the MCT8 thyroid hormone transporter. J Med Genet 2006, 43:457-460.

7. Zoeller RT, Rovet J: Timing of thyroid hormone action in the developing brain: Clinical observations and experimental findings. Journal of Neuroendocrinology 2004, 16:809-818.

8. Zoeller TR, Dowling AL, Herzig CT, lannacone EA, Gauger KJ, Bansal R: Thyroid hormone, brain development, and the environment. Environ Health Perspect 2002, 110(Suppl 3):355-361.

9. Bernal J: lodine and brain development. Biofactors 1999, 10:271-276.

10. Wirth EK, Roth S, Blechschmidt C, Holter SM, Becker L, Racz I, Zimmer A, Klopstock T, Gailus-Durner V, Fuchs H, et al: Neuronal 3',3,5triiodothyronine (T3) uptake and behavioral phenotype of mice deficient in Mct8, the neuronal T3 transporter mutated in Allan-Herndon-Dudley syndrome. J Neurosci 2009, 29:9439-9449.

11. Dumitrescu AM, Liao XH, Weiss RE, Millen K, Refetoff S: Tissue-specific thyroid hormone deprivation and excess in monocarboxylate transporter (mct) 8-deficient mice. Endocrinology 2006, 147:4036-4043.

12. Trajkovic M, Visser TJ, Mittag J, Horn S, Lukas J, Darras VM, Raivich G, Bauer $\mathrm{K}$, Heuer $\mathrm{H}$ : Abnormal thyroid hormone metabolism in mice lacking the monocarboxylate transporter 8. J Clin Invest 2007, 117:627-635.

13. Roberts LM, Woodford K, Zhou M, Black DS, Haggerty JE, Tate EH, Grindstaff KK, Mengesha W, Raman C, Zerangue N: Expression of the thyroid hormone transporters monocarboxylate transporter-8 (SLC16A2) and organic ion transporter-14 (SLCO1C1) at the blood-brain barrier. Endocrinology 2008, 149:6251-6261.

14. Friesema EC, Ganguly S, Abdalla A, Manning Fox JE, Halestrap AP, Visser TJ: Identification of monocarboxylate transporter 8 as a specific thyroid hormone transporter. J Biol Chem 2003, 278:40128-40135.

15. Heuer H, Maier MK, Iden S, Mittag J, Friesema EC, Visser TJ, Bauer K: The monocarboxylate transporter 8 linked to human psychomotor 
retardation is highly expressed in thyroid hormone-sensitive neuron populations. Endocrinology 2005, 146:1701-1706.

16. Friesema EC, Jansen J, Visser TJ: Thyroid hormone transporters. Biochem Soc Trans 2005, 33:228-232

17. de Boer AG, van dS I, Gaillard PJ: The role of drug transporters at the blood-brain barrier. Annu Rev Pharmacol Toxicol 2003, 43:629-656.

18. Verrey F, Meier C, Rossier G, Kuhn LC: Glycoprotein-associated amino acid exchangers: broadening the range of transport specificity. Pflugers Arch 2000, 440:503-512.

19. Nakamura E, Sato M, Yang H, Miyagawa F, Harasaki M, Tomita K, Matsuoka S, Noma A, Iwai K, Minato N: 4F2 (CD98) heavy chain is associated covalently with an amino acid transporter and controls intracellular trafficking and membrane topology of 4F2 heterodimer. J Biol Chem 1999, 274:3009-3016.

20. Sato H, Tamba M, Ishii T, Bannai S: Cloning and expression of a plasma membrane cystine/glutamate exchange transporter composed of two distinct proteins. J Biol Chem 1999, 274:11455-11458.

21. Gasol E, Jimenez-Vidal M, Chillaron J, Zorzano A, Palacin M: Membrane topology of system xc- light subunit reveals a re-entrant loop with substrate-restricted accessibility. J Biol Chem 2004, 279:31228-31236.

22. Kim JY, Kanai Y, Chairoungdua A, Cha SH, Matsuo H, Kim DK, Inatomi J, Sawa $H$, Ida $Y$, Endou H: Human cystine/glutamate transporter: cDNA cloning and upregulation by oxidative stress in glioma cells. Biochim Biophys Acta 2001, 1512:335-344.

23. Abe T, Kakyo M, Sakagami H, Tokui T, Nishio T, Tanemoto M, Nomura H, Hebert SC, Matsuno S, Kondo H, et al: Molecular characterization and tissue distribution of a new organic anion transporter subtype (oatp3) that transports thyroid hormones and taurocholate and comparison with oatp2. J Biol Chem 1998, 273:22395-22401.

24. Huang Y, Lemieux MJ, Song J, Auer M, Wang DN: Structure and mechanism of the glycerol-3-phosphate transporter from Escherichia coli. Science 2003, 301:616-620

25. Manoharan C, Wilson MC, Sessions RB, Halestrap AP: The role of charged residues in the transmembrane helices of monocarboxylate transporter 1 and its ancillary protein basigin in determining plasma membrane expression and catalytic activity. Mol Membr Biol 2006, 23:486-498.

26. Kinne A, Kleinau G, Hoefig CS, Gruters A, Kohrle J, Krause G, Schweizer U: Essential molecular determinants for thyroid hormone transport and first structural implications for monocarboxylate transporter 8. J Biol Chem 2010, 285:28054-28063.

27. Westholm DE, Marold JD, Viken KJ, Duerst AH, Anderson GW, Rumbley JN: Evidence of Evolutionary Conservation of Function between the Thyroxine Transporter Oatp1c1 and Major Facilitator Superfamily Members. Endocrinology 2010, 151(12):5941-5951.

28. Abramson J, Smirnova I, Kasho V, Verner G, Kaback HR, Iwata S: Structure and mechanism of the lactose permease of Escherichia coli. Science 2003, 301:610-615.

29. Guan L, Mirza O, Verner G, Iwata S, Kaback HR: Structural determination of wild-type lactose permease. Proc Natl Acad Sci U S A 2007, 104:15294-15298.

30. Shaffer PL, Goehring A, Shankaranarayanan A, Gouaux E: Structure and mechanism of a Nat-independent amino acid transporter. Science 2009, 325:1010-1014

31. Yamashita A, Singh SK, Kawate T, Jin Y, Gouaux E: Crystal structure of a bacterial homologue of $\mathrm{Na}+/ \mathrm{Cl}$-dependent neurotransmitter transporters. Nature 2005, 437:215-223.

32. Ianculescu AG, Friesema EC, Visser TJ, Giacomini KM, Scanlan TS: Transport of thyroid hormones is selectively inhibited by 3-iodothyronamine. $\mathrm{Mol}$ Biosyst 2010, 6:1403-1410

33. Kim DK, Kanai Y, Chairoungdua A, Matsuo H, Cha SH, Endou H: Expression cloning of a $\mathrm{Na}$--independent aromatic amino acid transporter with structural similarity to $\mathrm{H}+$ /monocarboxylate transporters. J Biol Chem 2001, 276:17221-17228

34. Friesema EC, Jansen J, Jachtenberg JW, Visser WE, Kester MH, Visser TJ: Effective cellular uptake and efflux of thyroid hormone by human monocarboxylate transporter 10. Mol Endocrinol 2008, 22:1357-1369.

35. Kalliokoski A, Niemi M: Impact of OATP transporters on pharmacokinetics. Br J Pharmacol 2009, 158:693-705.

36. König J, Seithel A, Gradhand U, Fromm MF: Pharmacogenomics of human OATP transporters. Naunyn Schmiedebergs Arch Pharmacol 2006, 372:432-443.
37. Tohyama K, Kusuhara H, Sugiyama Y: Involvement of multispecific organic anion transporter, Oatp14 (Slc21a14), in the transport of thyroxine across the blood-brain barrier. Endocrinology 2004, 145:4384-4391.

38. Sugiyama $D$, Kusuhara $H$, Taniguchi $H$, Ishikawa $S$, Nozaki $Y$, Aburatani $H_{\text {, }}$ Sugiyama Y: Functional characterization of rat brain-specific organic anion transporter (Oatp14) at the blood-brain barrier: high affinity transporter for thyroxine. J Biol Chem 2003, 278:43489-43495.

39. Pizzagalli F, Hagenbuch B, Stieger B, Klenk U, Folkers G, Meier PJ: Identification of a novel human organic anion transporting polypeptide as a high affinity thyroxine transporter. Mol Endocrinol 2002, 16:2283-2296.

40. Visser WE, Friesema EC, Jansen J, Visser TJ: Thyroid hormone transport in and out of cells. Trends Endocrinol Metab 2008, 19:50-56.

41. Wagner CA, Lang F, Broer S: Function and structure of heterodimeric amino acid transporters. Am J Physiol Cell Physiol 2001, 281:C1077-C1093.

42. Segawa H, Fukasawa Y, Miyamoto K, Takeda E, Endou H, Kanai Y: Identification and functional characterization of a $\mathrm{Na}$-independent neutral amino acid transporter with broad substrate selectivity. J Biol Chem 1999, 274:19745-19751.

43. Friesema EC, Docter R, Moerings EP, Verrey F, Krenning EP, Hennemann G, Visser TJ: Thyroid hormone transport by the heterodimeric human system L amino acid transporter. Endocrinology 2001, 142:4339-4348.

44. Bannai S, Kitamura E: Transport interaction of L-cystine and L-glutamate in human diploid fibroblasts in culture. J Biol Chem 1980, 255:2372-2376.

45. Bannai S, Kitamura E: Role of proton dissociation in the transport of cystine and glutamate in human diploid fibroblasts in culture. J Biol Chem 1981, 256:5770-5772.

46. Bannai $\mathrm{S}$ : Exchange of cystine and glutamate across plasma membrane of human fibroblasts. J Biol Chem 1986, 261:2256-2263.

47. Heuer H, Visser TJ: Minireview: Pathophysiological importance of thyroid hormone transporters. Endocrinology 2009, 150:1078-1083.

48. del Amo EM, Urtti A, Yliperttula M: Pharmacokinetic role of L-type amino acid transporters LAT1 and LAT2. Eur J Pharm Sci 2008, 35:161-174.

49. Pfeiffer R, Spindler B, Loffing J, Skelly PJ, Shoemaker CB, Verrey F: Functional heterodimeric amino acid transporters lacking cysteine residues involved in disulfide bond. FEBS Lett 1998, 439:157-162.

50. Palacin M, Nunes V, Font-Llitjos M, Jimenez-Vidal M, Fort J, Gasol E, Pineda M, Feliubadalo L, Chillaron J, Zorzano A: The genetics of heteromeric amino acid transporters. Physiology (Bethesda) 2005, 20:112-124.

51. Konig J, Seithel A, Gradhand U, Fromm MF: Pharmacogenomics of human OATP transporters. Naunyn Schmiedebergs Arch Pharmacol 2006, 372:432-443.

52. Halestrap AP, Meredith D: The SLC16 gene family-from monocarboxylate transporters (MCTs) to aromatic amino acid transporters and beyond. Pflugers Arch 2004, 447:619-628.

53. Kirk P, Wilson MC, Heddle C, Brown MH, Barclay AN, Halestrap AP: CD147 is tightly associated with lactate transporters MCT1 and MCT4 and facilitates their cell surface expression. EMBO J 2000, 19:3896-3904

54. Hemler ME, Strominger JL: Characterization of antigen recognized by the monoclonal antibody (4F2): different molecular forms on human $T$ and B lymphoblastoid cell lines. J Immunol 1982, 129:623-628.

55. Chillaron J, Roca R, Valencia A, Zorzano A, Palacin M: Heteromeric amino acid transporters: biochemistry, genetics, and physiology. Am J Physiol Renal Physiol 2001, 281:F995-1018

56. Boado RJ, Li JY, Chu C, Ogoshi F, Wise P, Pardridge WM: Site-directed mutagenesis of cysteine residues of large neutral amino acid transporter LAT1. Biochim Biophys Acta 2005, 1715:104-110.

57. Bassi MT, Gasol E, Manzoni M, Pineda M, Riboni M, Martin R, Zorzano A, Borsani G, Palacin M: Identification and characterisation of human xCT that co-expresses, with 4F2 heavy chain, the amino acid transport activity system xc-. Pflugers Arch 2001, 442:286-296.

58. Badagnani I, Castro RA, Taylor TR, Brett CM, Huang CC, Stryke D, Kawamoto M, Johns SJ, Ferrin TE, Carlson EJ, et al: Interaction of methotrexate with organic-anion transporting polypeptide $1 \mathrm{~A} 2$ and its genetic variants. J Pharmacol Exp Ther 2006, 318:521-529.

59. van der Deure WM, Peeters RP, Visser TJ: Molecular aspects of thyroid hormone transporters, including MCT8, MCT10, and OATPs, and the effects of genetic variation in these transporters. $J$ Mol Endocrinol 2010, 44:1-11.

60. Boado RJ, Li JY, Pardridge WM: Site-directed mutagenesis of rabbit LAT1 at amino acids 219 and 234. J Neurochem 2003, 84:1322-1331. 
61. Broer A, Friedrich B, Wagner CA, Fillon S, Ganapathy $V$, Lang F, Broer S: Association of $4 \mathrm{~F} 2 \mathrm{hc}$ with light chains LAT1, LAT2 or $\mathrm{y}+\mathrm{LAT} 2$ requires different domains. Biochem J 2001, 355:725-731.

62. Jimenez-Vidal M, Gasol E, Zorzano A, Nunes V, Palacin M, Chillaron J: Thiol modification of cysteine 327 in the eighth transmembrane domain of the light subunit $\mathrm{xCT}$ of the heteromeric cystine/glutamate antiporter suggests close proximity to the substrate binding site/permeation pathway. J Biol Chem 2004, 279:11214-11221.

63. Lee W, Glaeser H, Smith LH, Roberts RL, Moeckel GW, Gervasini G, Leake BF, Kim RB: Polymorphisms in human organic anion-transporting polypeptide 1A2 (OATP1A2): implications for altered drug disposition and central nervous system drug entry. J Biol Chem 2005, 280:9610-9617.

64. Bonen A, Heynen M, Hatta H: Distribution of monocarboxylate transporters MCT1-MCT8 in rat tissues and human skeletal muscle. Appl Physiol Nutr Metab 2006, 31:31-39.

65. Chan SY, Franklyn JA, Pemberton HN, Bulmer JN, Visser TJ, McCabe CJ, Kilby MD: Monocarboxylate transporter 8 expression in the human placenta: the effects of severe intrauterine growth restriction. $J$ Endocrinol 2006, 189:465-471.

66. Di Cosmo C, Liao XH, Dumitrescu AM, Philp NJ, Weiss RE, Refetoff S: Mice deficient in MCT8 reveal a mechanism regulating thyroid hormone secretion. J Clin Invest 2010, 120:3377-3388.

67. Halestrap AP, Meredith D: The SLC16 gene family-from monocarboxylate transporters (MCTs) to aromatic amino acid transporters and beyond. Pflugers Arch 2004, 447:619-628.

68. Nishimura M, Naito S: Tissue-specific mRNA expression profiles of human solute carrier transporter superfamilies. Drug Metab Pharmacokinet 2008, 23:22-44.

69. Gill RK, Saksena S, Alrefai WA, Sarwar Z, Goldstein JL, Carroll RE, Ramaswamy K, Dudeja PK: Expression and membrane localization of MCT isoforms along the length of the human intestine. Am J Physiol Cell Physiol 2005, 289:C846-C852.

70. Friesema EC, Docter R, Moerings EP, Stieger B, Hagenbuch B, Meier PJ, Krenning EP, Hennemann G, Visser TJ: Identification of thyroid hormone transporters. Biochem Biophys Res Commun 1999, 254:497-501.

71. Glaeser H, Bailey DG, Dresser GK, Gregor JC, Schwarz UI, McGrath JS, Jolicoeur E, Lee W, Leake BF, Tirona RG, et al: Intestinal drug transporter expression and the impact of grapefruit juice in humans. Clin Pharmacol Ther 2007, 81:362-370.

72. Fujiwara K, Adachi H, Nishio T, Unno M, Tokui T, Okabe M, Onogawa T, Suzuki T, Asano N, Tanemoto M, et al: Identification of thyroid hormone transporters in humans: different molecules are involved in a tissuespecific manner. Endocrinology 2001, 142:2005-2012.

73. Cheng X, Maher J, Chen C, Klaassen CD: Tissue distribution and ontogeny of mouse organic anion transporting polypeptides (Oatps). Drug Metab Dispos 2005, 33:1062-1073.

74. Rossier G, Meier C, Bauch C, Summa V, Sordat B, Verrey F, Kuhn LC: LAT2, a new basolateral $4 \mathrm{~F} 2 \mathrm{hc} / \mathrm{CD} 98$-associated amino acid transporter of kidney and intestine. J Biol Chem 1999, 274:34948-34954.

75. Umeki N, Fukasawa Y, Ohtsuki S, Hori S, Watanabe Y, Kohno Y, Terasaki T: mRNA expression and amino acid transport characteristics of cultured human brain microvascular endothelial cells (hBME). Drug Metab Pharmacokinet 2002, 17:367-373.

76. Kanai $Y$, Segawa H, Miyamoto K, Uchino H, Takeda E, Endou H: Expression cloning and characterization of a transporter for large neutral amino acids activated by the heavy chain of 4F2 antigen (CD98). J Biol Chem 1998, 273:23629-23632.

77. Yanagida O, Kanai Y, Chairoungdua A, Kim DK, Segawa H, Nii T, Cha SH, Matsuo H, Fukushima J, Fukasawa Y, et al: Human L-type amino acid transporter 1 (LAT1): characterization of function and expression in tumor cell lines. Biochim Biophys Acta 2001, 1514:291-302.

78. Ohkame H, Masuda H, Ishii Y, Kanai Y: Expression of L-type amino acid transporter 1 (LAT1) and 4F2 heavy chain (4F2hc) in liver tumor lesions of rat models. J Surg Oncol 2001, 78:265-271.

79. Pinho MJ, Serrao MP, Gomes P, Hopfer U, Jose PA, Soares-da-Silva P: Overexpression of renal LAT1 and LAT2 and enhanced L-DOPA uptake in SHR immortalized renal proximal tubular cells. Kidney Int 2004, 66:216-226.

80. Kobayashi Y: Localization of the System L Amino Acid Transporters LAT1 and LAT2 in Rat Gastrointestinal Tract. Journal of the Kyorin Medical Society 2007, 38:75-84.
81. Braun D, Kinne A, Brauer AU, Sapin R, Klein MO, Kohrle J, Wirth EK, Schweizer U: Developmental and cell type-specific expression of thyroid hormone transporters in the mouse brain and in primary brain cells. Glia 2011, 59:463-471.

82. Bassi MT, Sperandeo MP, Incerti B, Bulfone A, Pepe A, Surace EM, Gattuso C, De Grandi A, Buoninconti A, Riboni M, et al: SLC7A8, a gene mapping within the lysinuric protein intolerance critical region, encodes a new member of the glycoprotein-associated amino acid transporter family. Genomics 1999, 62:297-303.

83. Pineda M, Fernandez E, Torrents D, Estevez R, Lopez C, Camps M, Lloberas J, Zorzano A, Palacin M: Identification of a membrane protein, LAT-2, that Co-expresses with 4F2 heavy chain, an L-type amino acid transport activity with broad specificity for small and large zwitterionic amino acids. J Biol Chem 1999, 274:19738-19744.

84. Sato H, Tamba M, Kuriyama-Matsumura K, Okuno S, Bannai S: Molecular cloning and expression of human $x C T$, the light chain of amino acid transport system xc-. Antioxid Redox Signal 2000, 2:665-671.

85. Burdo J, Dargusch R, Schubert D: Distribution of the cystine/glutamate antiporter system xc- in the brain, kidney, and duodenum. J Histochem Cytochem 2006, 54:549-557.

86. Friesema EC, Kuiper GG, Jansen J, Visser TJ, Kester MH: Thyroid hormone transport by the human monocarboxylate transporter 8 and its ratelimiting role in intracellular metabolism. Mol Endocrinol 2006, 20:2761-2772.

doi:10.1186/1756-6614-4-S1-S7

Cite this article as: Kinne et al:: Primary and secondary thyroid hormone transporters. Thyroid Research 2011 4(Suppl 1):S7.

\section{Submit your next manuscript to BioMed Central and take full advantage of:}

- Convenient online submission

- Thorough peer review

- No space constraints or color figure charges

- Immediate publication on acceptance

- Inclusion in PubMed, CAS, Scopus and Google Scholar

- Research which is freely available for redistribution 